\title{
The use of electrodialysis with mono-anion permselective membranes for defluoridation
}

\author{
Martyna Grzegorzek ${ }^{1, *}$, and Katarzyna Majewska-Nowak ${ }^{1}$ \\ ${ }^{1}$ Wrocław University of Science and Technology, Department of Environmental Engineering, \\ Wybrzeże Wyspiańskiego 27, 50-370 Wrocław, Poland
}

\begin{abstract}
Water contamination by fluoride is a common problem present in many regions of the world. The excess of fluorine leads to many health issues. For that reason, the World Health Organisation estimated the permissible fluoride concentration to $1.5 \mathrm{mg} \mathrm{F}^{-} / \mathrm{dm}^{3}$. In this paper defluoridation process with the use of electrodialysis was described. During research standard cation-exchange (PC-SK) and mono-anion permselctive membranes (PC-MVA) were applied. The current density was equal to $1.72 \mathrm{~mA} / \mathrm{cm}^{2}$ (it corresponded with a current intensity equal to $0.11 \mathrm{~A}$ ) in the course of experiments. The tested solutions contained fluoride, organic matter (humic acids) and sodium chloride. The volume of diluate and concentrate was equal to $2 \mathrm{dm}^{3}$ each. The fluoride concentration amounted to $5,10,100$ and $200 \mathrm{mg} \mathrm{F}^{-} / \mathrm{dm}^{3}$. The sodium chloride content amounted to $0.5 \mathrm{~g} \mathrm{NaCl} / \mathrm{dm}^{3}$, whereas humic acids concentration was equal to 5,10 and $15 \mathrm{mg} / \mathrm{dm}^{3}$. It has been noticed that the fluoride content has influenced on the energy demand, removal efficiency and process duration. In few cases electrodialysis allowed to decrease the fluoride content under permissible level for drinking water and the $\mathrm{F}^{-}$removal efficiency was very satisfying for the most part.
\end{abstract}

\section{Introduction}

Fluorine is a common chemical element. It migrates to the environment from two sources natural and anthropogenic. Some amount of fluoride migrates to water by dissolving rocks and soils which contain fluoride (like biotite, fluorite, topaz, cryolite, villiaumite) [1-3]. In wastewater from phosphoric acid production, the $\mathrm{F}^{-}$concentration can reach even $3000 \mathrm{mg}$ $\mathrm{F}^{-} / \mathrm{dm}^{3}$. Fluoride also migrates to the environment from ceramic production, food industry, fertilizer manufacturing or electroplating $[4,5]$. Due to the harmful impact on human health, the World Health Organisation estimated the permissible level of fluoride in drinking water to $1.5 \mathrm{mg} \mathrm{F} / \mathrm{dm}^{3}[1,6]$. Exceeded concentration of fluoride leads to many health issues - dental and skeleton fluorosis, neurological problems, lesions of the thyroid or cancer. In small amount fluorine is beneficial for human health - it is one of the main constituents of bones and tooth $[2,5,7]$.

Water contamination by fluoride was observed in many regions of the world [3]. It has been estimated that even 200 million people consume water of $\mathrm{F}^{-}$ion content over the

${ }^{*}$ Corresponding author: martyna.grzegorzek@pwr.edu.pl 
permissible level [1, 2]. In India and China 26 and 35 million people are exposed to fluoride contamination, respectively [8]. The elevated concentration was observed e.g. in India, China, Pakistan, Morocco. In Tanzania the $\mathrm{F}^{-}$ion content in groundwater reached even $330 \mathrm{mg} \mathrm{F}^{-} / \mathrm{dm}^{3}$. In Kenya the fluoride content of $180 \mathrm{mg} \mathrm{F}^{-} / \mathrm{dm}^{3}$ has been noticed [4, 9, 10$]$. In Tanzania fluoride contamination is so significant that it was necessary to increase the permissible level of $\mathrm{F}^{-}$ions in drinking water to $4 \mathrm{mg} \mathrm{F}^{-} / \mathrm{dm}^{3}$. It has been also noticed that in Tanzania fluoride occurs in water simultaneously with organic matter [1].

There are many possible ways of fluoride removal from drinking water - ion exchange, adsorption, precipitation or membrane techniques (i.e. electrodialysis (ED), reverse osmosis (RO), nanofiltration (NF), Donnan dialysis (DD), electrocoagulation) [2, 3, 7, 11, 12]. Most of the conventional methods have disadvantages - the necessity of troublesome regeneration, low capacity and selectivity or high costs. For that reason membrane processes became more popular [4].

Organic matter $(\mathrm{OM})$ is a common constituent in water bodies. Usually, the $\mathrm{OM}$ concentration varies from 0.5 to $100 \mathrm{mg} \mathrm{C} / \mathrm{dm}^{3}$. There is a risk of formation of highly toxic and cancerogenic disinfection-by products as THMs during chlorine disinfection due to the presence of organic matter. OM also has a negative impact on water taste and color. Humic substances (HS) constitute $50-90 \%$ of natural organic matter in surface waters. Their concentration in rivers or lakes can reach even $30 \mathrm{mg} / \mathrm{dm}^{3}$ [13], whereas in groundwater HS concentration is usually low (approx. $0.02 \mathrm{mg} / \mathrm{dm}^{3}$ ). Humic acids (HAs) are made of aromatic rings bound to a phenolic hydroxyl $(-\mathrm{OH})$ and carboxyl (-COOH) groups [14]. Besides, they can react with metal ions, oxides, hydroxides and form macromolecules soluble or insoluble in water. The behaviour of HAs in water environment and soils depends on their dissociation ability and solubility. What else, they can be used in soil fertilization $[15,16]$. It has been observed that humic acid particles, which are negatively charged in neutral $\mathrm{pH}$, can be responsible for fouling phenomenon during electrodialysis. Usually, organic matter particles are predominantly deposited on anion-exchange membranes [17].

Banasiak et. al [17] did research into fluoride removal with the use of ED in the presence of organic matter. They examined the influence of various organic matter substances (humic acids, HAs; tannic acids, TAs; alginic acid, AAs) on defluoridation efficiency. They applied AMX-SB and CMX-SB membranes (Astom, Japan). The initial fluoride concentration was equal to $5 \mathrm{mg} \mathrm{F}^{-} / \mathrm{dm}^{3}$. The fluoride removal was independent of $\mathrm{pH}$ for experiments without $\mathrm{OM}$ addition and it was equal to $65.6 \pm 12 \%$. The flux of $\mathrm{F}^{-}$ions reached $10 \mathrm{mmol} / \mathrm{m}^{2} \mathrm{~h}$. In the presence of TAs, the average percentage of fluorides removed was $74.8 \%$. Similar fluoride removal efficiency was obtained when treated solutions contained AAs and HAs and it was equal to 72.9 and $72.5 \%$, respectively. An insignificant decrease of $\mathrm{F}^{-}$ion flux has also been noticed.

Arda et al. [18] also did research into fluoride removal from water with the use of ED. They applied CMX and AMX membranes. During experiments water from Balcova (Izmir, Turkey) geothermal power plant region was used. They tested two different technological variants. In the first one the $\mathrm{pH}$ of water was adjusted to $7.0-7.5$ by adding the $\mathrm{HCl}$ acid before ED operation. This acidification allowed minimization of risk of divalent salt precipitation. In the second method, the chemical pretreatment was used. For this purpose $1.0 \mathrm{mmol} / \mathrm{dm}^{3}$ of $\mathrm{Na}_{2} \mathrm{CO}_{3}$ and $1.5 \mathrm{mmol} / \mathrm{dm}^{3}$ of $\mathrm{NaOH}$ was added to treated water what allowed precipitation of calcium ions. The initial fluoride concentration in treated solution amounted to $7.72 \mathrm{mg} \mathrm{F}^{-} / \mathrm{dm}^{3}$. Application of the first method allowed lowering of the $\mathrm{F}^{-}$ion concentration to $0.06 \mathrm{mg} \mathrm{F}^{-} / \mathrm{dm}^{3}$. In the second variant, the final fluoride content was equal to $0.07 \mathrm{mg} \mathrm{F}^{-} / \mathrm{dm}^{3}$.

Amor et al. [19] conducted experiments on the fluoride removal from brackish water with the use of ED process. They used standard cation-exchange membranes (CMX) and monoanion permselective membranes (ACS). During experiments model fluoride solutions were 
used (the content of model solutions reflected the composition of Algerian water). Fluoride content amounted to $3 \mathrm{mg} \mathrm{F} / \mathrm{dm}^{3}$. The influence of voltage, flow and temperature on defluoridation efficiency was examined. Three voltage values $(5,10$ and $15 \mathrm{~V})$ were verified. The fluoride content was lowered to $2.87,0.67$ and $0.21 \mathrm{mg} \mathrm{F}^{-} / \mathrm{dm}^{3}$, respectively. Two values of flow rate $\left(50\right.$ and $180 \mathrm{dm}^{3} / \mathrm{h}$ ) were also examined during experiments. The final fluoride concentration was equal to 1.79 and $0.67 \mathrm{mg} \mathrm{F}^{-} / \mathrm{dm}^{3}$, respectively. Three temperatures (16, 25 and $4^{\circ} \mathrm{C}$ ) were also verified. It was found that the fluoride removal efficiency increased with increasing temperature. At $16^{\circ} \mathrm{C}$ the final fluoride content was lowered to $1.95 \mathrm{mg} \mathrm{F} / \mathrm{dm}^{3}$. When the temperature was elevated to $25^{\circ} \mathrm{C}$, the final fluoride content reached $0.67 \mathrm{mg} \mathrm{F}^{-} / \mathrm{dm}^{3}$. The best result was obtained at $40^{\circ} \mathrm{C}$ - in this case the final $\mathrm{F}^{-}$content decreased to $0.60 \mathrm{mg} \mathrm{F}^{-} / \mathrm{dm}^{3}$.

Lahnid et al. [20] performed economical evaluation of fluoride removal by electrodialysis. The desired water production amounted to $100 \mathrm{~m}^{3} / \mathrm{h}$. The ACS and CMX-Sb membranes were applied and the ED stack consisted of 1000 cells. The total cost of installation was estimated as $833,207 €$. The initial fluoride content was equal to $2.32 \mathrm{mg} / \mathrm{dm}^{3}$ and it was lowered to $1 \mathrm{mg} / \mathrm{dm}^{3}$. The flow of raw water reached $106.32 \mathrm{~m}^{3} / \mathrm{h}$. Energy for water pumping was calculated as $0.4 \mathrm{kWh} / \mathrm{m}^{3}$, whereas energy for desalination reached $0.464 \mathrm{kWh} / \mathrm{m}^{3}$. This means that the costs of energy needed to defluoridation was equal to $0.046 € / \mathrm{m}^{3}$. Also, it has been estimated that the operating costs for treatment of $1 \mathrm{~m}^{3}$ of fluoride containing water amounted to $0.154 € / \mathrm{m}^{3}$.

The aim of this paper was to evaluate the usability of electrodialysis with mono-anion permselective membranes for fluoride removal from water solutions in the presence of organic matter. Special attention was paid on the ED process efficiency for wide range of fluoride concentration in tested solution $\left(5-200 \mathrm{mg} \mathrm{F}^{-} / \mathrm{dm}^{3}\right)$.

\section{Methodology and reagents}

\subsection{Reagents}

In the experiments model solutions made of sodium fluoride $(\mathrm{NaF})$ and sodium chloride $(\mathrm{NaCl})$ were used. Fluoride concentration was equal to 5, 10, 100 and $200 \mathrm{mg} \mathrm{F}^{-} / \mathrm{dm}^{3}$. Mineral salt content amounted to $0.5 \mathrm{~g} \mathrm{NaCl} / \mathrm{dm}^{3}$ (approx. $300 \mathrm{mg} \mathrm{Cl} / \mathrm{dm}^{3}$ ). Humic acids (HAs) in the amount of 5,10 and $15 \mathrm{mg} / \mathrm{dm}^{3}$ were also added to the model solutions. The colour intensity caused by the presence of organic matter was equal to 25,50 and $75 \mathrm{mg} \mathrm{Pt} / \mathrm{dm}^{3}$.

\subsection{Installation and membranes}

Experiments were conducted with the use of ED installation PCCell BED-1-System. The membrane stack consisted of 10 pairs of diluate and concentrate cells. 11 standard cationexchange (PC-SK) and 10 mono-anion permselective (PC-MVA) membranes were applied. Membranes and installation were purchased from PCCell GmbH (Germany). The volume of diluate and concentrate amounted to $2 \mathrm{dm}^{3}$ (each). Concentrate contained fluoride and sodium chloride, whereas diluate was supplemented with humic acids.

\subsection{Methodology}

Fluoride content was measured by colorimetric method with SPADNS reagent. Fluoride creates colorless complexes with zirconium present in the reagent. In effect, the higher fluoride content the lesser color of the sample. Measurements were conducted with the use 
of Hach 2000 spectrophotometer (wavelength $580 \mathrm{~nm}$, method no. 8029, program 190). Method accuracy amounted to $\pm 9 \%$.

The current intensity was established at $0.11 \mathrm{~A}$ what corresponded to a current density of $1.72 \mathrm{~mA} / \mathrm{cm}^{2}$.

With the aim of energy demand calculations, the volatage was monitored at certain time intervals in the course of ED process. The specific electrical energy demand was calculated according to the following equation (1):

$$
E C=\frac{0}{V_{d}^{t} u d t}
$$

where: $E C$ - specific electrical energy demand $\left(\mathrm{kWh} / \mathrm{m}^{3}\right), I$ - current intensity (A), $U$ - voltage $(\mathrm{V}), V_{d}$ - the volume of the diluate $\left(\mathrm{m}^{3}\right), t$ - process duration (h).

Chloride content was measured according to Mohr method with silver nitrate and potassium chromate.

\section{Results}

\subsection{Final fluoride concentration}

In view of the ED process usability, the most important is the final diluate quality. The final fluoride concentration in relation to humic acids content is shown in Fig. 1.

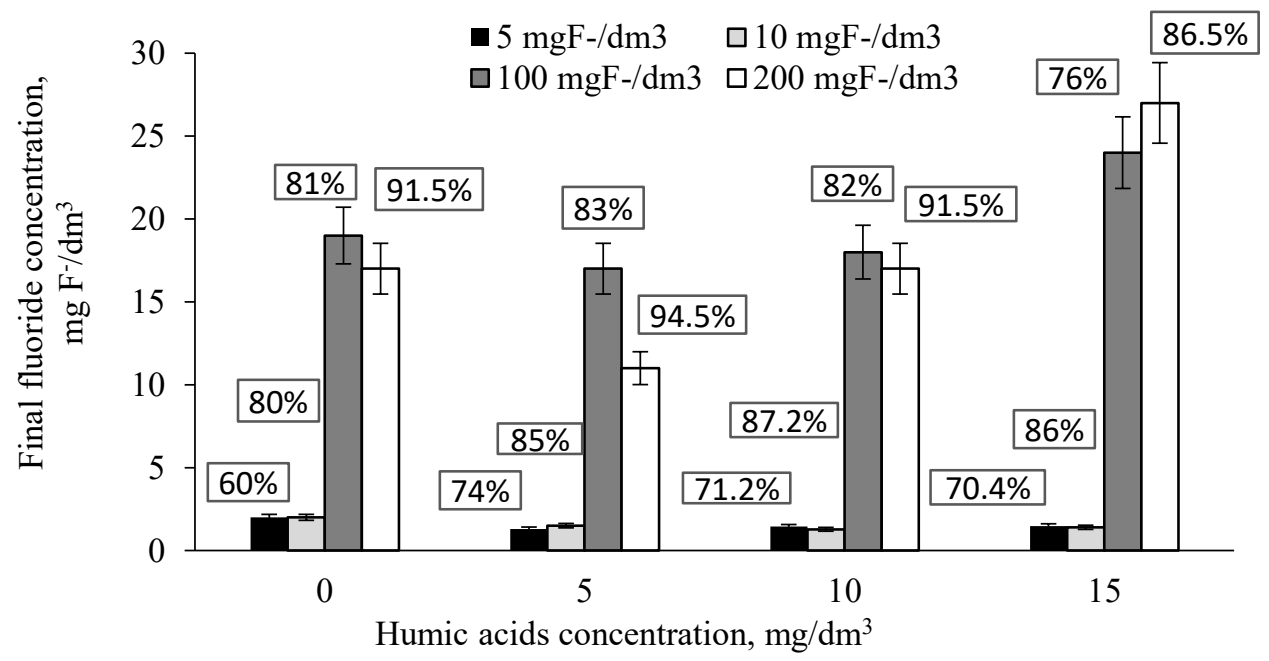

Fig. 1. Final fluoride concentration and removal efficiency versus initial fluoride concentration and humic acids content (current density $1.72 \mathrm{~mA} / \mathrm{cm}^{2}$, error bars $\pm 9 \%$ ).

For solutions containing $5 \mathrm{mg} \mathrm{F} / \mathrm{dm}^{3}$ the fluoride content was lowered to $1.3-2 \mathrm{mg} \mathrm{F}^{-} / \mathrm{dm}^{3}$ what corresponded with defluoridation efficiency between $60 \%$ and $74 \%$. The worst results were observed during experiments without organic matter presence in the tested solutions. When HAs content was equal to $5 \mathrm{mg} \mathrm{F}^{-} / \mathrm{dm}^{3}$, the final fluoride concentration 
was lowered to $1.3 \mathrm{mg} \mathrm{F}^{-} / \mathrm{dm}^{3}$. Similar results were found for the increased fluoride content $\left(10 \mathrm{mg} \mathrm{F}^{-} / \mathrm{dm}^{3}\right)$. The final $\mathrm{F}^{-}$concentration in diluate varied from 1.28 to $2 \mathrm{mg} \mathrm{F}^{-} / \mathrm{dm}^{3}$, what meant that $80-87.2 \%$ of $\mathrm{F}^{-}$ions was removed. Generally, in most experiments with initial fluoride concentration of 5 and $10 \mathrm{mg} \mathrm{F}^{-} / \mathrm{dm}^{3}$, the final $\mathrm{F}^{-}$ion content was lowered below the permissible limit $\left(1.5 \mathrm{mg} \mathrm{F}^{-} / \mathrm{dm}^{3}\right)$.

The results obtained for electrodialysis of solutions containing significantly elevated amounts of fluorides (100 and $200 \mathrm{mg} \mathrm{F} / \mathrm{dm}^{3}$ ) were less promising than for low initial fluoride content ( 5 and $10 \mathrm{mg} \mathrm{F}^{-} / \mathrm{dm}^{3}$ ). The fluoride concentration in diluate was much higher than permissible level and varied from 11 to $27 \mathrm{mg} \mathrm{F}^{-} / \mathrm{dm}^{3}$. The best results were observed for the lowest HAs content and the highest initial $\mathrm{F}^{-}$concentration $(94.5 \%$ of fluoride was removed). However, it was found that with increasing concentration of organic matter in diluate, the removal efficiency of $\mathrm{F}^{-}$ions deteriorated reaching 76 and $86.5 \%$ for the initial fluoride content of 100 and $200 \mathrm{mg} \mathrm{F}^{-} / \mathrm{dm}^{3}$, respectively.

Analysis of the exerimental results also revealed that the fluoride content affected the ED process duration (data not shown). The average time of the process was equal to $21 \mathrm{~min}$ when the initial $\mathrm{F}^{-}$ion concentration was low (5 and $\left.10 \mathrm{mg} \mathrm{F}^{-} / \mathrm{dm}^{3}\right)$, irrespectively of the organic matter concentration. At high initial fluoride concentration $\left(100\right.$ and $\left.200 \mathrm{mg} \mathrm{F}^{-} / \mathrm{dm}^{3}\right)$ the average process duration was extended to 33 and $46 \mathrm{~min}$, respectively. The obtained results are in compliance with Faraday's law - a time of the process is proportional to the amount of ions which are needed to be removed.

The obtained results allowed to state that organic matter has a slight influence on the defluoridation efficiency. The presence of organic matter insignificantly enhanced the removal efficiency of $\mathrm{F}^{-}$ions. This relationship was more pronounced for electrodialysis of solutions with low fluoride content. One of the explanations for this phenomenon is an interaction between fluoride ions and macroparticles of humic acids. It is possible that fluoride ions are trapped inside the big structure of humic acid particles (,open-cage” concept) without the involvement of bounding to functional groups. The dissociated particles of HAs can be deposited on the surface of anion-exchange membranes. The second possibility is that cations $\left(\mathrm{Na}^{+}\right)$are attracted to negatively charged HAs particles and then fluoride anions are able to bind to them [21].

\subsection{Final chloride concentration}

In the experiments multicomponent solutions were subjected to the ED process, therefore the fate of chlorides, as competitive anions, was also examined. The final chloride concentration in diluate in relation to humic acids and fluoride concentration is given in Fig. 2.

Excellent chloride removal (90.8-98.3\%) was obtained irrespectively of the composition of tested solutions. In general, the final $\mathrm{Cl}^{-}$ion concentration in diluate amounted to approx. 5-34 $\mathrm{mg} \mathrm{Cl}^{-} / \mathrm{dm}^{3}$. The worst result ( $88.8 \%$ removal efficiency) however, still promising, was found for the highest HAs content $\left(15 \mathrm{mg} / \mathrm{dm}^{3}\right)$ and low initial fluoride concentration $\left(10 \mathrm{mg} \mathrm{F}^{-} / \mathrm{dm}^{3}\right)$. Electrodialysis with solutions containing only $\mathrm{Cl}^{-}$and $\mathrm{F}^{-}$ions (the latter ions in low concentration) arrived at the final chloride concentration of $28 \mathrm{mg} \mathrm{Cl}^{-} / \mathrm{dm}^{3}$. Analysing the results given in Fig. 2, it evident that the best $\mathrm{Cl}^{-}$removal efficiency was received for solutions containing moderate amounts of HAs $\left(5\right.$ and $\left.10 \mathrm{mg} / \mathrm{dm}^{3}\right)$ and elevated content of fluorides (100 and $\left.200 \mathrm{mg} \mathrm{F}^{-} / \mathrm{dm}^{3}\right)$.

It should be emphasized that chloride removal efficiency (Fig.2) was significantly better than the percentage of fluoride removal (Fig.1). This finding can be simply explained by differences in ion mobility and hydrated radius size of the discussed ions. Fluoride ions are characterized by a lower mobility and bigger radius than $\mathrm{Cl}^{-}$ions. The hydrated radius of $\mathrm{F}^{-}$ion is equal to $0.352 \mathrm{~nm}$, whereas the radius of $\mathrm{Cl}^{-}$ion is $0.332 \mathrm{~nm}$ [17]. The ion mobility equals to 7.91 and $5.70 \mathrm{~m}^{2} / \mathrm{sV}$ for $\mathrm{Cl}^{-}$and $\mathrm{F}^{-}$ions, respectively [17]. For that reason, chloride 
ions can be transported and removed more easily (especially through mono-anion permselective membranes) than fluoride ions. The impact of coexisting ions on $\mathrm{F}^{-}$ion transport through ion-exchange membranes has been reported in the literature [17].

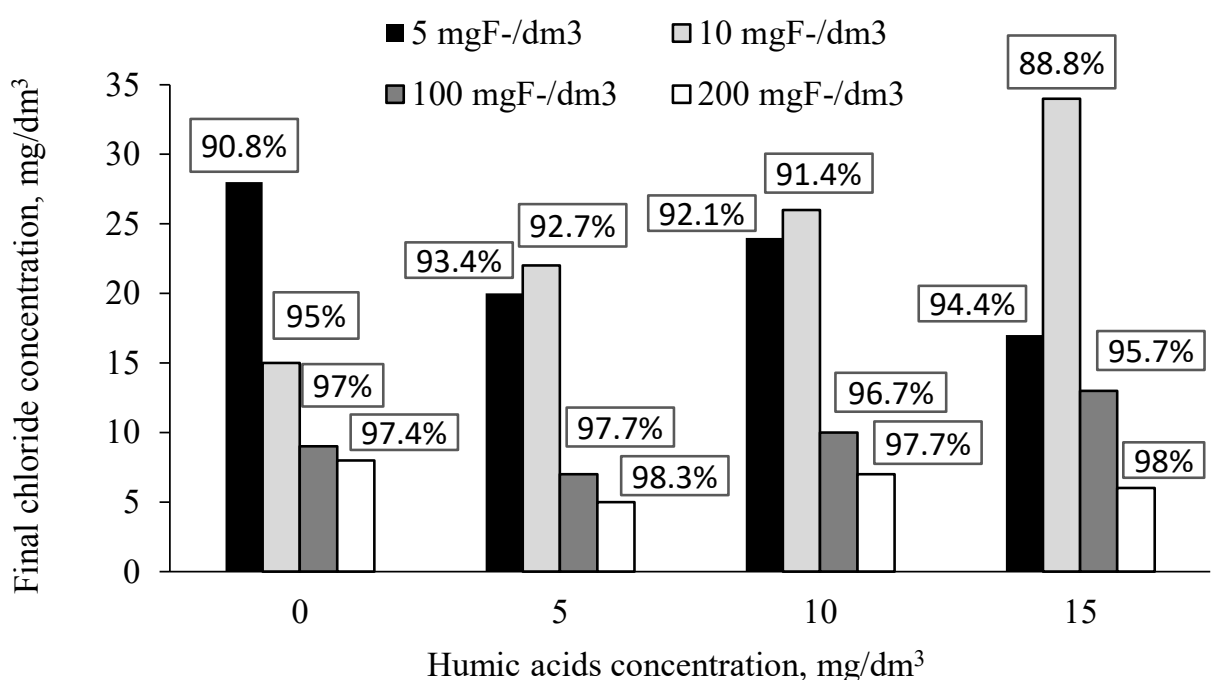

Fig. 2. Final chloride content and removal efficiency versus initial fluoride concentration and humic acids content (current density $1.72 \mathrm{~mA} / \mathrm{cm}^{2}, \mathrm{C}_{0}=303 \mathrm{mg} \mathrm{Cl}^{-} / \mathrm{dm}^{3}$ ).

The influence of HAs presence in tested solutions on $\mathrm{Cl}^{-}$ion removal can be neglected. It can be anticipated that small and mobile $\mathrm{Cl}^{-}$ions are able to overcome the resistance of HAs layer deposited at the surface of mono-anion exchange membrane, irrespectively of deposition intensity (i.e. HAs concentration).

Unexpectedly, the effect of $\mathrm{F}^{-}$ion concentration on the $\mathrm{Cl}^{-}$ion removal was strongly confirmed (Fig. 2) - with increasing fluoride concentration the efficiency of chloride removal improved evidently. It seems that the increase in ionic strength of the tested solution facilitates transport of chloride ions through mono-anion permselective membranes. This beneficial effect does not occur in the case of fluoride ions which are less mobile than chloride ions.

\subsection{Specific electrical energy demand}

Energy demand is a crucial parameter for potential end-users, thus the specific electrical energy demand was calculated according to the equation 1 . The obtained results are shown in Fig. 3.

Due to rather low content of mineral salts in tested solutions, the calculated energy demand was also low and varied in the range of approx. $0.2-0.5 \mathrm{kWh} / \mathrm{m}^{3}$. The lowest EC was observed for solutions without HAs addition, whereas the highest energy demand occurred when the content of organic matter in the treated solutions amounted to $10 \mathrm{mg} / \mathrm{dm}^{3}$. Basically, an increase in energy demand was noted with increasing HAs content. This relationships seems to be reasonable keeping in mind that humic acids are well-known foulants and can be easily deposited at the membrane surface, thus increasing the electrical resistance of the ED stack. Consequently, more energy is needed for desalination process. 
Nonetheless, the greatest variation in energy usage was induced by fluoride content. This finding was especially pronounced for ED experiments with solutions containing elevated amounts of fluorides (100 and $\left.200 \mathrm{mg} \mathrm{F}^{-} / \mathrm{dm}^{3}\right)$ - the EC calculated for ED of solutions containing $200 \mathrm{mg} \mathrm{F}^{-} / \mathrm{dm}^{3}$ was even by $25-30 \%$ greater than the EC obtained in the course of ED with fluoride concentration of $100 \mathrm{mg} \mathrm{F}^{-} / \mathrm{dm}^{3}$. An even greater difference in energy consumption (almost two-fold) was detected between ED tests for low and high fluoride content (5-10 and $200 \mathrm{mg} \mathrm{F} / \mathrm{dm}^{3}$, respectively) at HAs concentration of $10 \mathrm{mg} / \mathrm{dm}^{3}$. The observed dependence between the electrical energy demand and salt concentration clearly arises from Faraday's low.

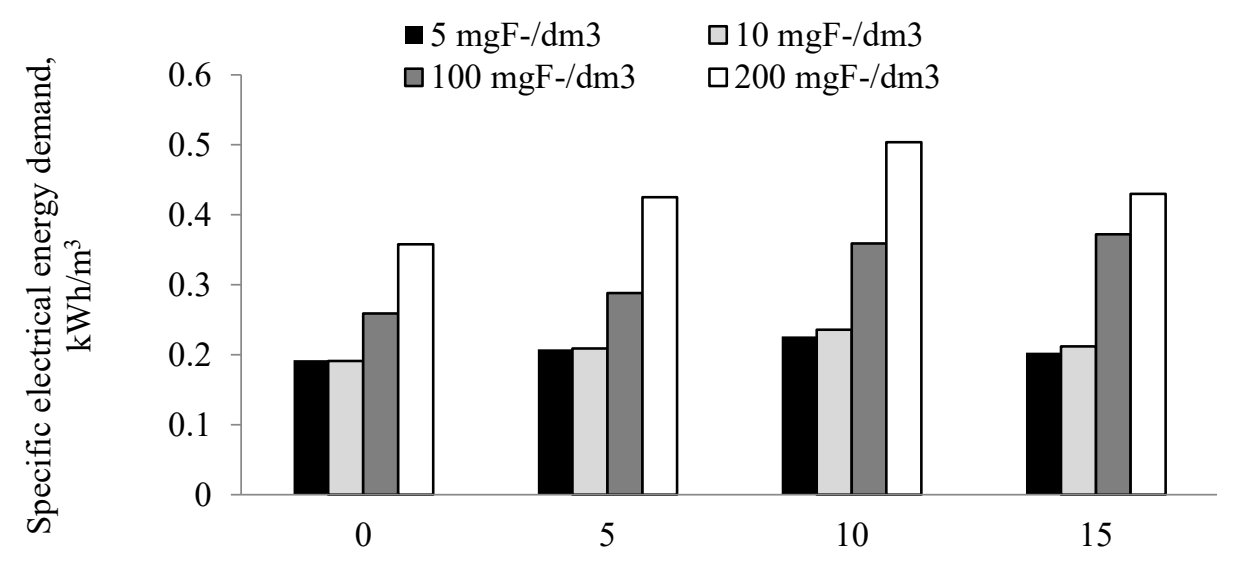

Humic acids concentration, $\mathrm{mg} / \mathrm{dm}^{3}$

Fig. 3. Specific electrical energy demand versus initial fluoride concentration and humic acids content (current density $1.72 \mathrm{~mA} / \mathrm{cm}^{2}$ ).

\section{Conclusions}

- Electrodialysis of multicomponent fluoride solutions with the use of mono-anion permselective membranes enabled satisfactory diminishing of $\mathrm{F}^{-}$ion concentration. In most cases at low initial fluoride content $\left(5\right.$ and $10 \mathrm{mg} \mathrm{F}^{-} / \mathrm{dm}^{3}$ ) the final $\mathrm{F}^{-}$ion concentrations did not exceed the permissible level $\left(1.5 \mathrm{mg} \mathrm{F}^{-} / \mathrm{dm}^{3}\right)$ for drinking water. At elevated fluoride concentration $\left(100\right.$ and $\left.200 \mathrm{mg} \mathrm{F}^{-} / \mathrm{dm}^{3}\right)$ high $\mathrm{F}^{-}$removal efficiency (approx. 90\%) was also possible.

- The presence of organic matter in treated solutions had a slight impact on the fluoride removal efficiency. An insignificant improvement of fluoride separation might be caused by trapping $\mathrm{F}^{-}$ions inside macroparticles of humic acids.

- The chloride removal efficiency during electrodialysis of multicomponent solutions was notably better than the fluoride separation efficiency. Chloride ions can be transported and removed more easily (especially through mono-anion permselective membranes) due to higher ion mobility and smaller hydrated radius than ion mobility and radius size of fluoride ions.

- The fluoride content had the greatest impact on the specific electrical energy demand. The expected deposition of organic matter at/in ion-exchange membranes resulted in a moderate increase of energy demand. 
- Electrodialysis of water highly contaminated by fluoride ions should be proceeded by preliminary treatment. An integrated treatment system should have beneficial influence on the overall process performance, as well as on the electrodialysis cost. It can be also supposed that pre-tretament will contribute to reduce fouling in electrodialysis stack and prolongate the membrane life cycle.

\section{References}

1. J. Shen, A.I. Schäfer, Sci. Total Environ. 527-528, 520 (2015)

2. S. Gogoi, R.K. Dutta, Environ. Chem. Eng. 4, 1040 (2016)

3. L. Deng, Y. Liu, T. Huang, T. Sun, Chem. Eng. J. 287, 83 (2016)

4. I. Bejaoui, A. Mnif, B. Hamrouni, Sep. Sci. Technol. 49, 1135 (2014)

5. A. Boubakri, R. Bouchrit, A. Hafiane, S. A.-T. Bouguecha, Environ. Sci. Pollut. Res. 21, 10493 (2014)

6. S. Levin, S. Krishnan, S. Rajkumar, N. Haley, P. Balkunde, Sci. Total Environ. 551-552, 101 (2016)

7. K. Govindan, M. Raja, S.U. Maheshwari, M. Noel, Y. Oren, Environ. Chem. Eng. 3, 1784 (2015)

8. S.V. Jadhav, E. Bringas, G.D. Yadav, V.K. Rathod, I. Ortiz, K.V. Marathe, J. Environ. Manage. 162, 306 (2015)

9. S. Chatterjee, S. De, Sep. Sci. Technol. 125, 223 (2014)

10. J. Shen, A. Schäfer, Chemosphere 117, 679 (2014)

11. A. Boubakri, N. Helali, M. Tlili, M.B. Amor, Korean J. Chem. Eng. 31, 3, 461 (2014)

12. A. Vinati, B. Mahanty, S.K. Behera, Appl. Clay Sci. 114, 340 (2015)

13. M. Wang, L. Liao, X. Zhang, Z. Li, Appl. Clay Sci. 67-68, 164 (2012)

14. K. Szymański, A.W. Morawski, S. Mozia, Chem. Eng. J. 305, 19 (2016)

15. M. Klučáková, React. Funct. Polym. 109, 9 (2016)

16. S. Zhang, L. Yuan, W. Li, Z. Lin, Y. Li, S. Hu, B. Zhao, Chemosphere 166, 334 (2017)

17. L.J. Banasiak, A.I. Schäfer, J. Membr. Sci. 334, 101 (2009)

18. M. Arda, E. Orhan, O. Arar, M. Yuksel, N. Kabay, Sep. Sci. Technol. 44, 841 (2009)

19. Z. Amor, B. Bariou, N. Mameri, M. Taky, S. Nicolas, A. Elmidaoui, Desalination 133, 215 (2001)

20. S. Lahnid, M. Tahaikt, K. Elaroui, I. Idrissi M. Hafsi, I. Laaziz, Z. Amor, F. Tiyal, A. Elmidaoui, Desalination 230, 213 (2008)

21. J. Shen, S. Gagliardi, M.R.S. McCoustra, V. Arrighi, Chemosphere 159, 66 (2016) 